\title{
Spatial statistics detect clustering patterns of kidney diseases in south-eastern Romania
}

\author{
Faculty of Natural and Agricultural Sciences, Ovidius University of Constanţa, Romania \\ 2 "Sf. Apostol Andrei" Clinical Emergency Hospital of Constanţa, Romania \\ ${ }^{3}$ Faculty of Medicine, "Ovidius" University of Constanţa, Romania
}

\begin{abstract}
Medical geography was conceptualized almost ten years ago due to its obvious usefulness in epidemiological research. Still, numerous diseases in many regions were neglected in these aspects of research, and the prevalence of kidney diseases in Eastern Europe is such an example. We evaluated the spatial patterns of main kidney diseases in south-eastern Romania, and highlighted the importance of spatial modeling in medical management in Romania. We found two statistically significant hotspots of kidney diseases prevalence. We also found differences in the spatial patterns between categories of diseases. We propose to speed up the process of creating a national database of records on kidney diseases. Offering the researchers access to a national database will allow further epidemiology studies in Romania and finally lead to a better management of medical services.
\end{abstract}

Keywords: Hot Spot Analysis, medical geography, chronic kidney disease, acute kidney injury, Romania

\section{Cristina Preda}

"Ovidius" University of Constanţa,

The Faculty of Natural and Agricultural Sciences

Aleea Universitaţii nr. 1, corp B, Constanţa 900470, Romania

email: cristina.preda@univ-ovidius.ro

\section{Introduction}

Medical geography was conceptualized almost ten years ago due to its obvious usefulness in epidemiological research[1]. Since then, many spatial statistics and tests were applied on public health data in order to evaluate research questions such as space clusters of diseases, relation of these clusters with possible factors as waste and pollution sites, management of medical services, etc.[2]. The majority of the medical systems already evaluated the long term spatial patterns of different epidemics in their countries. For example, the researchers in Sweden scanned the spatial patterns of childhood leukemia occurring in the country over 20 years and found the disease records are randomly distributed in space[3]. This result may suggest in Sweden there is no obvious hotspot of air pollution (i.e., a region of oil processing industry), where the prevalence of childhood leukemia is expected to be higher.

Not only the pollution affects the human health, natural parameters in air, water, and food were also documented to determine health issues. For example, a high dietary calcium intake due to high calcium concentrations in drinking water increases the risk 
of kidney stones[4] and geographic variability of this affection was demonstrated[5].

In this paper we evaluate the spatial patterns of main kidney diseases in Constanta County, souteastern Romania, and highlighted the importance of spatial modeling in medical management in Romania.

\section{Methods}

The prevalence of kidney diseases was collected from patients hospitalized in Nephrology department, "Sf. Apostol Andrei" Clinical Emergency Hospital of Constanta, Romania, in two consecutive years, 2013 and 2014. Besides the diagnostic set after clinical investigations, we also recorded the home locality of each patient. These records were spatially aggregated with a GIS layer of administrative units of Constanta County. Census data from 2011 National Census were also aggregated to the same layer. We proceeded to calculate the ratio between the total number of patients and total population at the last census in order to reduce the skewed effect determined by the high population size of Constanta Metropolitan Area. This ratio was then plotted for different kidney diseases as well as for the entire dataset. We decided to plot the ratio in Standard Deviation Units in order to highlight the administrative units where a disease occurs more frequently than is expected at regional scale. Spatial patterns of the prevalence of kidney affections in Constanta County were analyzed using Getis Ord Gi* spatial statistic[6,7] implemented as Hot Spot Analysis in ArcGIS Desktop 10.1 (ESRI, CA). We used Euclidean Distance as a distance method since no apriority information is known about aggregation of kidney diseases prevalence in geographic space. We let the tool to estimate the threshold distance for creating the clusters of hot and cold spots of kidney affections according to the average size of the administrative units' polygons. A flow chart of our modeling steps is presented in Figure 1.

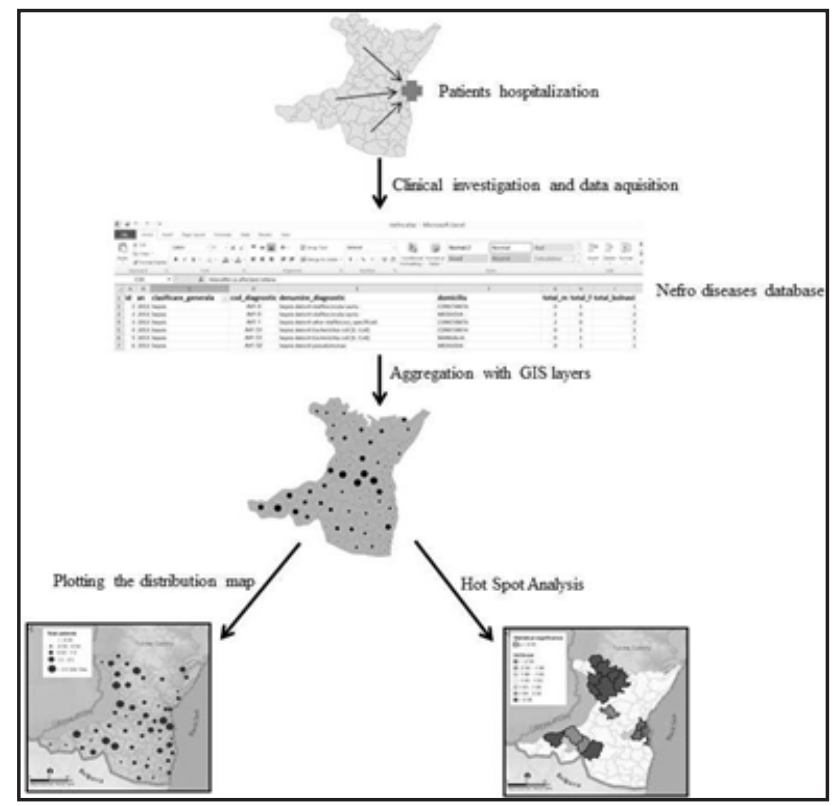

Figure 1 - Flow chart of the modelling steps used to account for spatial patterns in the distribution of nephrological patients across the Constanţa County.

\section{Results and discussion}

The ratio between total number of patients and total population at the last census revealed an obvious clustering pattern of geographic distribution across the Constanta County. There are three main clusters: a central one, along the west-east axis of Cernavoda, Medgidia and Constanta cities; a north-west one at Crucea-Pantelimon region; and a south-west one at Oltina-Adamclisi region. In these clusters, the ratio between patients and total population is often $2.5 \mathrm{Std}$. Dev. units above the County's average (Figure 2).

Getis-Org $\mathrm{Gi}^{*}$ statistic highlighted the hot and cold spots of patients hospitalized in 2013 and 2014. The map revealed the clusters where number of patients is significantly higher than expected by chance alone. The statistically significant hotspots $(\mathrm{p}<$ 0.05) were: i. Tortoman, Crucea, Pantelimon, Topalu, Horia, Vulturu, Saraiu, and Girliciu in north-western 
part of the County; and ii. Deleni, Adamclisi, Aliman, and Oltina in south-east, along the Danube (Figure 3 ). The only cluster that was significantly lower than the County's average (i.e., cold spot) was located on the Black Sea Coast, in Constanta Metropolitan Area (Figure 3). It was comprised by Constanta, Ovidiu, Agigea, and Valu lui Traian. This region acted as a cold spot due to the effect of high population size that reduced the ratio with nephrological patients.

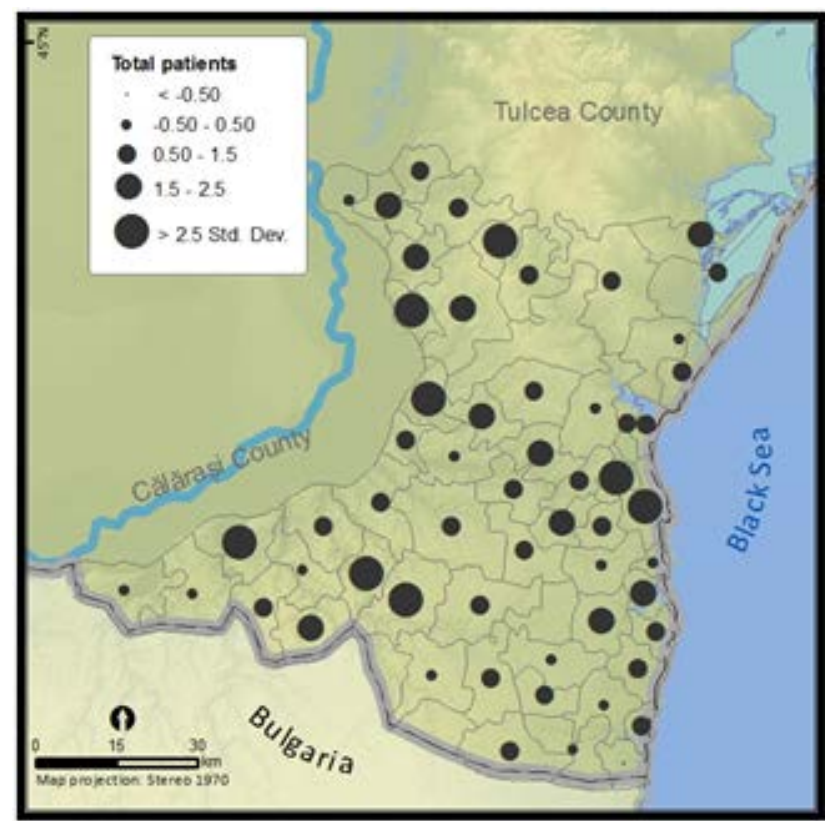

Figure 2 - The ratio between total number of patients hospitalized in Nephrology department at Constanta Hospital and total population at the last census. Number of patients is summed for 2013 and 2014. The ratio is plotted in Std. Dev. units bellow or above County's average.

Spatial analysis of main kidney diseases revealed different patterns across the Constanta County. Moderate chronic kidney disease $(\mathrm{eGFR}=30$ $60 \mathrm{ml} / \mathrm{min} / 1.73 \mathrm{sqm}$ ) is mostly affecting two clusters: first is Constanta Metropolitan Area and the second is Topalu-Vulturu area in north west (Figure 4A).

For severe chronic kidney disease (eGFR $=15$ $30 \mathrm{ml} / \mathrm{min} / 1.73 \mathrm{sqm}$ ), the spatial pattern was different: highest proportion of patients were from south-eastern part of the County, from Oltina, Adamclisi and Deleni. Constanta Metropolitan area was not highly affected although southwards, in Techirghiol, the number of patients were 2 Std. Dev. units above the average
(Figure 4B). Acute kidney injury is not affecting the entire County, only few regions having hospitalized patients: on the west part two outliers are Oltina and Topalu while the Black Sea Coast is moderately affected (Figure 4C). Tubulo-interstitial nephropathies are again affecting only parts of Constanta County. In the west part Topalu and Adamclisi were highlighted as outliers above average. In the east part the entire coastline was affected with Corbu-Sacele as the most affected region (Figure 4D).

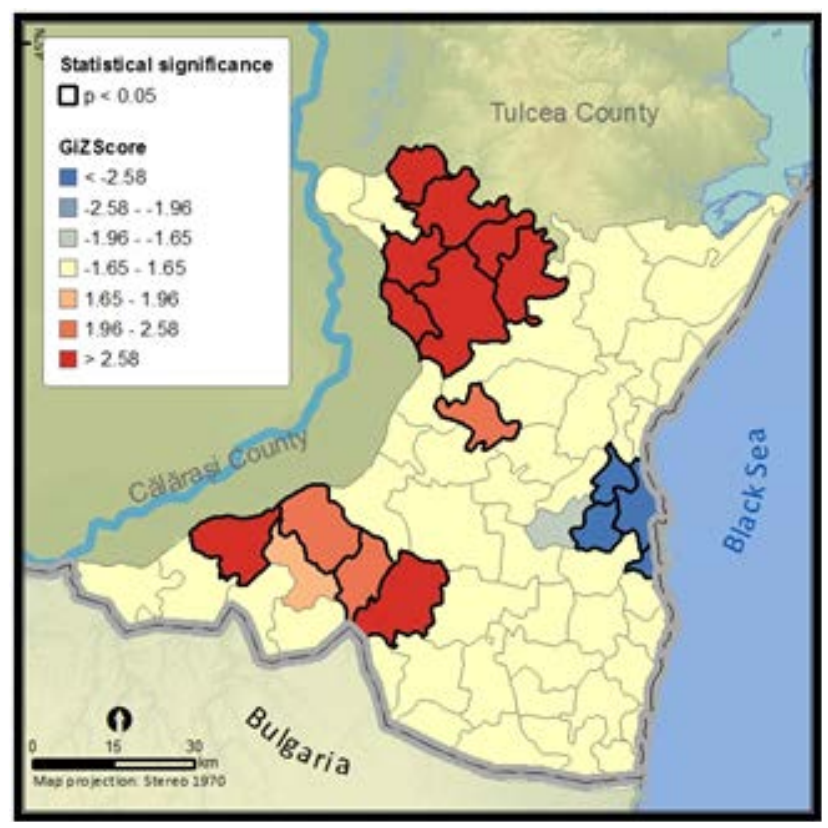

Figure 3 - Getis-Ord Gi* statistic was used on the ratio between number of nephrological patients and total population of the last census. It reveals hot spots (i.e., location where number of patients is significantly higher than expected by random chance) and cold spots (i.e., location where number of patients is significantly lower than expected by random chance).

Kidney diseases are a major public health problem, for example chronic kidney disease (CKD) seems to affect $9-11 \%$ of the general population, end-stages of the disease requiring high costs for dialysis and transplantation programs[8]. Despite increasing interest in the geographic aspects of kidney diseases epidemiology $[9,10]$ little is known about its prevalence, especially in Eastern Europe. Our results suggest that high spatial variability exists in the incidence of the studied kidney diseases. Thus, 
we are in accordance with studies that evaluated the phenomenon elsewhere in the world. For example, a study made between 2007 and 2009 found that regional variation exists in the prevalence of dialysisrequiring acute kidney injury in the United States[11]. In China for example, an epidemiologic study of chronic kidney disease suggest significant differences between urban districts (e.g., hematuria in $0.8 \%$ of the population in the district of Beijing and in $6.5 \%$ in the city of Guangzhou[12]). Chronic tubulointerstitial disease has also similar geographic prevalence. Its strong association with upper urothelial cancer determined scientists to even describe a so called
Balkan endemic nephropathy, which affects only some rural regions of southeastern Europe[13].

To better understand these spatial patterns in Romania, we consider mandatory to speed up the process of creating a national database of records on kidney diseases. This database should merge the available data from all central hospitals for a period of time as long as possible. Offering the researchers access to such a database will allow further epidemiology studies in Romania and finally lead to a better management of medical services.
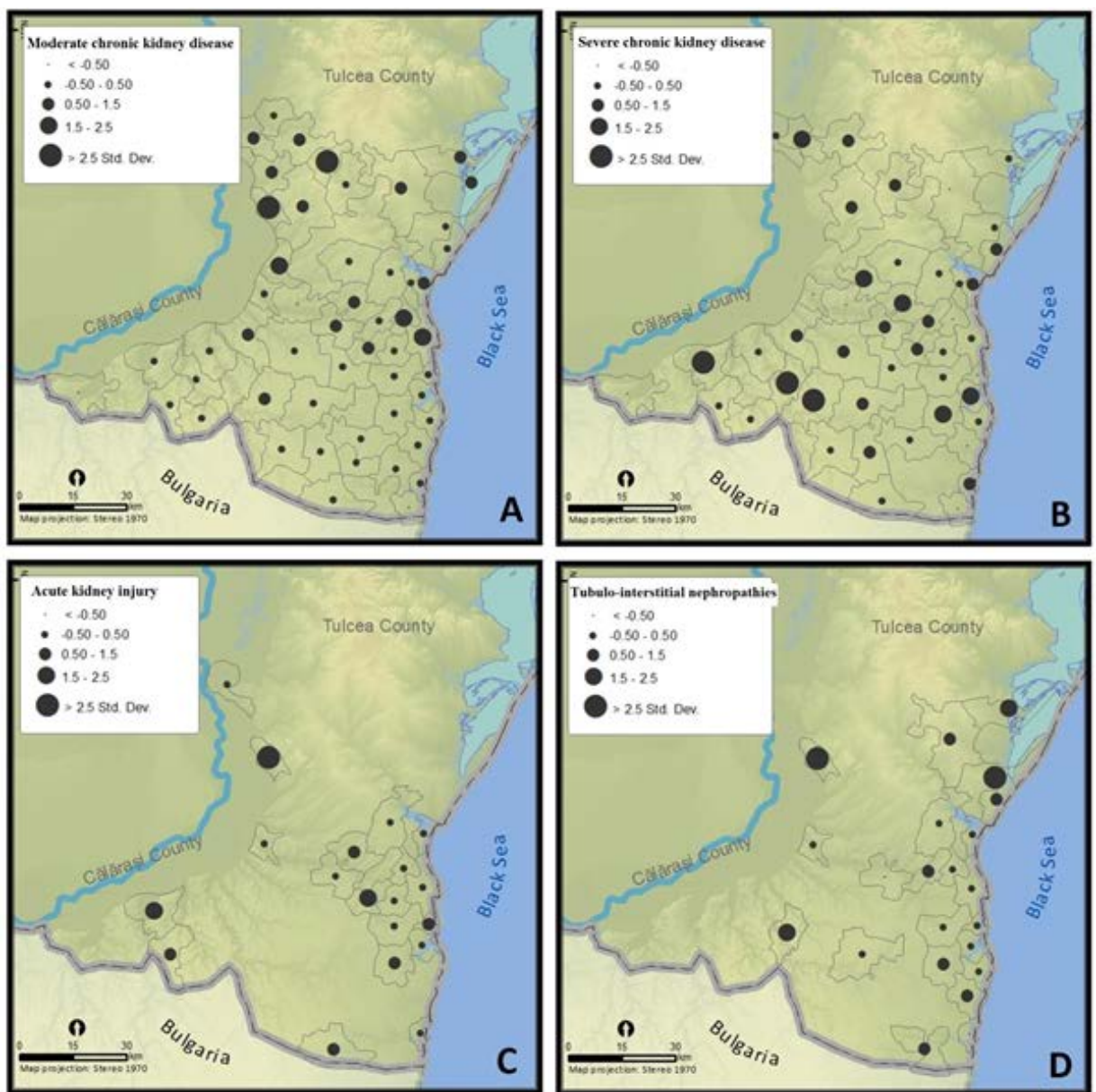

Figure 4 - The ratio between total number of patients hospitalized at Constanta Hospital and total population at the last census represented for four main kidney affection: A Moderate chronic kidney disease; $B$ - Severe chronic kidney disease; $C$-Acute kidney injury; D - Tubulo-interstitial nephropathies; Number of patients is summed for 2013 and 2014. The ratio is plotted in Std. Dev. units bellow or above County's average. 


\section{Acknowledgements}

This work received financial support through the project entitled "CERO - Career profile: Romanian Researcher", grant number POSDRU/159/1.5/S/135760, co-financed by the European Social Fund for Sectorial Operational Program Human Resources Development 2007-2013.

\section{References}

1. Gatrell, A.C. \& Bailey, T.C. (1996). Interactive spatial data analysis in medical geography. Social Science \& Medicine. 42(6), 843-855.

2. Waller, L.A. \& Gotway, C.A. (2004). Applied spatial statistics for public health data. New Jersey: John Wiley \& Sons, Inc.

3. Hjalmars, U.L.F., Kulldorff, M., Gustafsson, G. \& Nagarwalla N (1996) Childhood leukaemia in Sweden: Using GIS and a spatial scan statistic for cluster detection. Statistics in Medicine 15(79):707-715.

4. Curhan, G.C., (2007). Epidemiology of Stone Disease. Urologic Clinics of North America. 34(3), 287-293.

5. Soucie, J.M., Coates, R.J., McClellan, W.M., Austin, H. \& Thun, M. (1996). Relation between geographic variability in kidney stones prevalence and risk factors for stones. American Journal of Epidemiology 143(5), 487-495.

6. Getis, A. \& Ord, J.K. (2010). The analysis of spatial association by use of distance statistics. Geographical Analysis 24, 189-206.

7. Ord J.K. \& Getis, A. (1995). Local spatial autocorrelation statistics: distributional issues and an application. Geographical analysis. 27, 286-306.

8. Klebe, B., Irving, J., Stevens, P.E., O'Donoghue, D.J., de Lusignan, S., Cooley, R., Hobbs, H.,
Lamb, E.J., John, I., Middleton, R., New, J. \& Farmer, C.K. (2007). The cost of implementing UK guidelines for the management of chronic kidney disease. Nephrology Dialysis Transplantation. 22(9), 2504-2512.

9. McClellan, A.C., Plantinga, L. \& McClellan, W.M. (2012). Epidemiology, geography and chronic kidney disease. Current Opinion in Nephrology and Hypertension. 21, 323-328.

10. Stengel, B., Combe, C., Jacquelinet, C. et al. (2014). The French Chronic Kidney DiseaseRenal Epidemiology and Information Network (CKD-REIN) cohort study. Nephrology Dialysis Transplantation. 29(8), 1500-1507

11. Hsu, R.K., McCulloch, C.E., Ku, E., Dudley, R.A. \& Hsu, C. (2013). Regional Variation in the Incidence of Dialysis-Requiring AKI in the United States. Clinical Journal of the American Society of Nephrology : CJASN. 8(9), 1476-1481.

12. Xie, Y. \& Chen, X. (2008). Epidemiology, major outcomes, risk factors, prevention and management of Chronic Kidney Disease in China. Am J Nephrol 28, 1-7.

13. Stefanovic, V., Radovanovic, Z. (2008). Balkan endemic nephropathy and associated urothelial cancer. Nature Reviews Urology. 5(2), 105-112. 